\title{
Heat and Mass Transfer Analysis of Dehumidifiers Using Adiabatic Transient Tests
}

I. L. Maclaine-cross

University of New South Wales, Australia

\author{
A. A. Pesaran \\ SERI
}

April 1986

Prepared for the AIAA/ASME 4th

Thermo Physics and Heat Transfer

Conference; Boston, Massachusetts;

1-4 June 1986

Prepared under Task No. 3056.22

FTP No. 01-621

Solar Energy Research Institute

A Division of Midwest Research Institute

1617 Cole Boulevard

Golden, Colorado 80401-3393

Prepared for the

U.S. Department of Energy

Contract No. DE-AC02-83CH10093 


\section{NOTICE}

This report was prepared as an account of work sponsored by the United States Government. Neither the United States nor the United States Department of Energy, nor any of their employees, nor any of their contractors, subcontractors, or their employees, makes any warranty, expressed or implied, or assumes any legal liability or responsibility for the accuracy, completeness or usefulness of any information, apparatus, product or process disclosed, or represents that its use would not infringe privately owned rights.

Printed in the United States of America

Available from:

National Technical Information Service

U.S. Department of Commerce

5285 Port Royal Road

Springfield, VA 22161

Price: Microfiche A01

Printed Copy A02

Codes are used for pricing all publications. The code is determined by the number of pages in the publication. Information pertaining to the pricing codes can be found in the current issue of the following publications, which are generally available in most libraries: Energy Research Abstracts, (ERA); Government Reports Announcements and Index (GRA and 1); Scientific and Technical Abstract Reports (STAR); and publication, NTIS-PR-360 available from NTIS at the above address. 
HRAT AND MASS TRANSFER ANALYSIS OF DEHUMTDIFIERS USING ADIABATIC TRANSIENT TESTS

\author{
I. L. Maclaine-cross* \\ School of Mechanical and \\ Industrial Engineering \\ University of New South Wales \\ New South Wales, Australia
}

\author{
A. A. Pesaran \\ Solar Energy Research Institute \\ Golden, Colorado
}

\begin{abstract}
Adiabatic step transient data were obtained for two dehumidifier test matrices, using parallel plates with crushed silica gel and staggered parallel strips coated with microbead silica gel. The data were analyzed using the statistical moments method and combined heat and mass transfer analogy theory. The analysis showed that the average overall Nusselt number in both matrices was about $40 \%$ to 50\% lower than laminar flow predictions. The average overall Nusselt number for the microbead staggered matrix was about $85 \%$ larger than that of the crushed silica-gel parallel-plate matrix. The Nusselt number/friction factor Reynolds number ratio (Nu/fRe) of the microbead, staggered parallel-strip matrix was about $28 \%$ larger than that of the crushed silica-gel parallel-plate matrix. These results were explained by the presence of a stagnant gas film. The results showed that compact, high-performance, rotary dehumidifiers for desiccant cooling systems are possible and economical.
\end{abstract}

\section{Nomenclature}

A matrix wetted surface area of coated tape $\left(\mathrm{m}^{2}\right)$ A matrix minimum flow area $\left(\mathrm{m}^{2}\right)$

$c_{c}$ specific heat of carrier per unit mass of active desiccant ( $\mathrm{J} / \mathrm{kg} \mathrm{K}$ )

$C_{d}$ specific heat of desiccant $(\mathrm{J} / \mathrm{kg} \mathrm{K})$

$\mathrm{C}_{\mathrm{d}}$ specific heat of moist air ( $\mathrm{J} / \mathrm{kg} \mathrm{K}$ )

$C_{p C}^{P}$ apparent specific heat of carrier per unit mass of carrier ( $/ \mathrm{kg} \mathrm{K}$ )

$d_{h}$ hydraulic diameter $4 \mathrm{~A} c$ L/A (m)

dh particle diameter $(\mathrm{m})^{c}$

$D^{p}$ moisture diffusivity in air $\left(\mathrm{m}^{2} / \mathrm{s}\right)$

$D_{W}$ moisture diffusivity in particles $\left(\mathrm{m}^{2} / \mathrm{s}\right)$

f Fanning friction factor

$F_{i}$ ith combined potential

$\mathrm{h}$ enthalpy of moist air ( $\mathrm{J} / \mathrm{kg}$ )

$h$ convective heat transfer coefficient $\left(\mathrm{W} / \mathrm{m}^{2} \mathrm{~K}\right)$

$h_{\text {mc }}$ convective mass transfer coefficient $\left(\mathrm{kg} / \mathrm{m}^{2} \mathrm{~s}\right)$

mc overall mass transfer coefficient $\left(\mathrm{kg} / \mathrm{m}^{2} \mathrm{~s}\right)$

$\mathrm{h}$ overall heat transfer coefficient $\left(\mathrm{W} / \mathrm{m}^{2} \mathrm{~K}\right)$

$\mathrm{k}$ thermal conductivity of moist air (W/m K)

$\mathrm{k}^{\mathrm{a}}$ pressure-drop coefficient

$\mathrm{L}$ axial length of the matrix (m)

Le effective Lewis number

$m$ cumulative airflow mass ( $\mathrm{kg}$ )

ma dry air mass flow rate $(\mathrm{kg} / \mathrm{s})$

$\mathrm{m}_{\mathrm{d}}$ active mass of dry desiccant $(\mathrm{kg})$

$\mathrm{m}_{\text {des }}$ actual mass of dry desiccant ( $\mathrm{kg}$ )

$\mathrm{Nu}$ heat transfer Nusselt number

$\mathrm{Nu}_{\text {mo }}$ overall mass transfer Nusselt number

$\mathrm{Nu}$ overall heat transfer Nusselt number

$\mathrm{N}_{\text {tu }}$ number of heat transfer units

*Professor, Mechanical Engineering
Pf packing factor

Pr Prandt l number

$R_{d}$ ratio of effective mass to actual mass of dry desiccant

$R_{\text {t }}$ ratio of tape mass to dry desiccant mass

$R e$ Reynolds number

$T$ temperature $(\mathrm{K})$

$T^{\prime}$ dimensionless temperature

u mean air axial velocity in the channels $(\mathrm{m} / \mathrm{s})$

w humidity ratio ( $\mathrm{kg}$ water/kg dry air)

W desiccant water content ( $\mathrm{kg}$ water/kg dry desiccant)

\section{Greek}

$\alpha_{i} \quad-(\partial T / \partial w)_{F}$

$B_{2} \quad-(\partial h / \partial w)_{F}$

$Y_{i}$ specific Zapacity ratio $(\partial W / \partial w)_{F}{ }_{j}$

$\delta$ stagnant air thick

$\zeta$ solid-side geometry factor coefficient

$n_{\text {c }}$ solid-side geometry factor

$\theta$ time ( $s$ )

$\mu \quad$ statistical mean, also visçosity $\left(\mathrm{Ns} / \mathrm{m}^{2}\right)$

$\rho_{d}$ density of particles $\left(\mathrm{kg} / \mathrm{m}^{3}\right)$

d standard deviation

\section{Subscripts}

e at the end of a test

exp experimental

$i$ inlet value

int at intersection point

m mean value

o out value

$s$ at the start of a test

\section{Superscript}

- mean value

\section{Introduction}

\section{Background}

Solid desiccant cooling systems have recently received attention as competitors for conventional vapor compression air-conditioning systems in warm and humid climates. The desiccant cooling system involves process air (which is warm and humid) passing through a desiccant bed for drying and subsequent evaporative (direct or indirect) cooling to provide conditioned air. The desiccant bed becomes saturated and needs to be regenerated with hot air. Solar collectors or gas burners can provide the hot air. Since the cooling load increases as the solar gain increases, a good match exists between the required cooling and energy source when 
solar collectors are used. This makes solar desiccant cooling attractive.

A typical desiccant cooling system consists of two evaporative coolers, a regenerative heat exchanger, a (solar) heater, and an adiabatic desiccant dehumidifier. The open-cycle solid desiccant cooling systems can be competitive with vaporcompression air conditioning if the thermal coefficient of performance (COP) is greater than 1.2 .

Developing desiccant dehumidifiers with highperformance, low-pressure drop, and low cost is an important step in making the desiccant cooling systems competitive. The performance of a desiccant dehumidifier depends mainly on the type of desiccant used and the geometry of the dehumidifier. The most common material proposed for solar desiccant cooling applications is microporous silica-gel 1,2 .

The first geometry considered for dehumidifiers was a randomly packed bed of desiccant particles. The dynamic performance of packed beds was studied theoretically ${ }_{3}$ and experimentally by many investigators $3,4,5$. Kutscher and Barlow 6 found that the packed bed provided very low heattransfer-to-pressure-drop ratios and was economically unatractive for use in desiccant cooling applications. Because of their high heat-transferto-pressure-drop ratios, laminar flow channel geometries with walls having desiccant properties became very attractive to desiccant cooling researchers $7,8,9,10$.

The heat and mass transfer behavior of a dehumidifier should be characterized to evaluate its potential for use in desiccant cooling systems. Adiabatic transient tests of dehumidifiers have been used to provide such characterization $1,3,5,9,11$. Usually, the predictions of a heat and mass transfer model were compared and matched with the experimental curves, and heat and mass transfer coefficients and other information were extracted, although sometimes the matchings were just qualitative $1,3,5,9,10$. In heat (or mass) transfer alone problems, the heat (or mass) transfer coefficients can be estimated using the method of statistical moments 11,12 directly from the experimental data points, thus eliminating the subjective judgments. We used this method to characterize dehumidifier geometries.

In this study we obtained the adiabatic transient data on two innovative dehumidifier matrices: silica-gel parallel plate and silica-gel, staggered parallel strip. We developed a way to combine the heat and mass transfer analogy method 13,14 with the method of moments and analyzed the adiabatic transient data using this new method. This paper presents this analysis method, describes the experimental test rig and test dehumidifiers, and gives the analysis results and conclusions.

\section{Mathematical Analysis}

\section{Previous Step Transient Test Analyses}

Calculating dehumidifier matrix properties from the adiabatic temperature and humidity responses of a small test article to a step transient in inlet air state poses many difficulties. To do this we had to combine a number of literature theories and approximations, avoiding those with a high sensitivity to the instrumentation errors of the test rig.
Bullock and Threlkeld ${ }^{3}$ performed adiabatic step transient tests of a randomly packed bed of silicagel granules. They compared the outlet states with a finite difference solution and gbtained qualitative agreement. Pesaran and Mills $s^{5}$ performed adiabatic step transient tests on a bed of fine-crushed silica-gel particles. Two well-defined waves were obtained. They developed a heat and mass transfer model that properly accounted for solid-side diffusion resistance in the particles. Good agreement was obtained between experiments and finite difference solutions of the model used for dehumidification tests. For regeneration tests the agreement was qualitatively correct.

Kim et al. 9 performed adiabatic step transient tests on a bench-scale silica-gel parallel-plate dehumidifier. The experimental results obtained were compared with finite solutions of a lumped capacitance model. The agreement was generally good.

Schlepp and Barlow 10 obtained the adiabatic transient response of a small-scale silica-gel parallel-plate dehumidifier. The transient data were compared with the prediction of a pseudosteady-state heat and mass transfer model. In this model, effectiveness equations for steady-state counterflow heat or mass exchangers were used to predict the dehumidifier's performance. Predictions were in reasonable agreement with the experimental results for adsorption cases and were qualitative for desorption cases.

The literature discussed in the previous paragraph has used essentially the same method of interpreting the results of dehumidifier matrix: step transient tests. Graphs of the measured outlet temperature and humidity as a function of time were compared with numerical finite difference or approximate analytical solutions. It is difficult to make the curves match over a range of times and inlet states relevant to dehumidifiers and thereby confirm the validity of the properties and transfer coefficients used for the theoretical predictions.

Combined heat and mass transfer can be analyzed theoretically using D'Alembert's classical method of solving simultaneous differential equations by finding multipliers that convert the equations to a number of independent sets of equations in canonical variables. Each canonical variable appears in only one equation that can then be solved independently of the others. This approach was first applied to a combined heat and mass transfer system by Henry 13 . Banks 15 greatly improved the usefulness of this method by introducing the concept of combined potentials $F_{i}$ and combined specific capacity ratios $\gamma_{i}$.

The application of this method to the adiabatic step transient has been discussed by Banks et al. 16 and Close and Banks ${ }^{14}$. The enthalpy and moisture contents in the partial differential transport and conservation equations are replaced by the combined potentials of the air and the matrix. The equations are reduced to two sets of equations each describing the behavior of only one combined potential. Each set of equations is the same as the equations for heat transfer alone in a porous matrix. This method has often been called the analogy theory for heat and mass exchangers.

For constant matrix and fluid specific heat, Anzelius provided a solution to the problem of 
heat transfer alone in terms of Bessel functions. Literature tables and charts are ayailable on this subject, e.g., in Kays and London ${ }^{18}$. The transformed equations are analogous to those for heat transfer alone, the combined potentials are analogous to temperature in the transformed equations, and the combined specific capacity ratios are analogous to the ratio of matrix to fluid specific heat. For temperature ranges greater than $10 \mathrm{~K}$ (which usually occurs when operating dehumidifiers in desiccant cooling applications), a constant combined specific capacity ratio $Y_{j}$ is not a good approximation. Therefore, the Anzelius solution cannot be used for the two analogous problems of heat transfer alone.

The heat transfer coefficient is often calculated from the outlet temperatures in step transient tests of nondesiccant matrices using the method of statistical moments (e.g., Ruthven ${ }^{1}$ ). The dimensionless outlet temperature $T^{\prime}$ as a function $o^{f}$ time $\theta$ is a cumulative probability distribution ${ }^{18}$. From the definitions of statistical mean $\mu$ and standard deviation $\sigma$ as statistical moments of time with respect to dimensionless temperature, we can write

$$
\left(\frac{\sigma}{\mu}\right)^{2}=\frac{\int_{0}^{\infty} d T^{\prime} \int_{0}^{\infty} \theta^{2} d T^{\prime}}{\left(\int_{0}^{\infty} \theta d T^{\prime}\right)^{2}}-1 .
$$

It may be shown using Laplace transforms (e.g. Jefferson ${ }^{12}$ ) that the number of heat transfer units $N_{\text {tu }}$ for a constant specific heat system is related to the normalized spread $\sigma / \mu$ by

$$
\mathrm{N}_{\mathrm{tu}}=2 /(\sigma / \mathrm{H})^{2}
$$

The Nusselt number Nu may be readily calculated from the number of heat transfer units if flow rate, matrix dimensions, and fluid properties are known:

$$
\mathrm{Nu}=\operatorname{RePrN}_{t u} A_{c} / \mathrm{A} \text {. }
$$

The advantage of this moment method is that all data points can be used. Electronic digital data loggers have a high reading rate, and using all the data minimizes digitizing and other random errors.

Combined potential Nusselt numbers can be expressed in terms of the overall heat transfer Nusselt number $\mathrm{Nu}_{0}$, the effective Lewis number Le, and the combined potential coefficients $\alpha_{i}=-(\partial T / \partial w)_{F_{i}}$,

$$
\mathrm{Nu}_{i}=\mathrm{Nu}_{0}\left(\frac{1-\alpha_{i} / \alpha_{j} L_{e}}{1-\alpha_{i} / \alpha_{j}}\right) \quad i=1,2, j=3-i
$$

Calculation of Equilibrium, Transfer, and Flow Results

After the raw data from the step transient tests are collected, they are reduced to engineering units. Then we can search the reduced data for the start of the step change that occurs when the process air is introduced to the test matrix. The reduced data are also searched for the experimental intersection point and the end of the test run. The initial and final matrix states are calculated from the data. The following values are calculated: intersection point ( $w_{\text {int }}, \mathrm{T}_{\mathrm{int}}$ ) from the first combined potential $F_{1}$ through the inlet air state at the end of the run ( $w_{i e}, T_{i e}$ ), the second combined potential $F_{2}$ through the outlet air state at start of the run ( $\left.w_{o s}, T_{\rho s}\right)$, and the mean combined specific capacity ratio $\gamma_{2}$ down the $F_{1}$ line and $Y_{1}$ down the $F_{2}$ line. The classical fourth order Runge-Kutta method is used to integrate along lines of constant potentials. Note that $Y_{i}=(\partial W / \partial w) F_{j}$ for $j=3-i$.

The active mass of dry desiccant $m_{d}$ in the matrix is estimated from the moisture transferred between the process air and the desiccant and the equilibrium isotherms of the desiccant:

$$
m_{d}=\frac{\int_{\theta}^{\theta} e\left(w_{i}-w_{0}\right) \dot{m}_{a} d \theta}{w_{e}-w_{s}},
$$

where $\left(w_{e}-W_{s}\right)$ is the difference between the moisture content of the matrix at the start and the end of the run and is calculated from

$w_{e}-w_{s}=\bar{\gamma}_{1}\left(w_{i n t}-w_{O S}\right)+\bar{\gamma}_{2}\left(w_{i e}-w_{i n t}\right)$.

The ratio of effective mass to the actual mass of dry desiccant $R_{d}$ is

$$
R_{d}=m_{d} / m_{d e s} \text {. }
$$

The effective heat capacity of the carrier per unit mass of active desiccant $C_{c}$ is calculated next. Using the regula falsi method, the value of $C_{c}$ is obtained so the experimental value of $\gamma_{1}\left(\gamma_{1}\right.$,exp) is equal to the mean $\gamma_{1}$ calculated from the airdesiccant properties:

$$
\bar{\gamma}_{1}\left(c_{c}\right)=\gamma_{1, \exp } \cdot
$$

The apparent specific heat of the carrier $C$ (i.e., tape plus inactive desiccant) is then calcuc lated from

$$
C_{p c}=\left[C_{c}-C_{d}\left(1 / R_{d}-1\right)\right] / R_{t d},
$$

where $C_{d}$ is the specific heat of dry desiccant and $R_{t d}$ is the ratio of tape mass to actual dry desiccant mass.

The number of transfer units for each of the combined potentials is estimated using the moments of the combined potentials defined relative to the experimental intersection point. The cumulative airflow mass is calculated from

$$
\mathrm{m}_{\mathrm{a}}=\int_{\theta_{s}}^{\theta} \dot{\mathrm{m}}_{\mathrm{a}} \mathrm{d} \theta,
$$

to be used to estimate the normalized spread of the first combined potential:

$$
[(\sigma / \mu)]_{1}^{2}=\frac{\left(T_{o 1}-T_{o s}\right) \int_{\theta}^{\theta} 1_{s}^{2} d T_{0}}{\left(\int_{\theta_{s}}^{\theta} m_{a} d T_{0}\right)^{2}}-1 .
$$

Note that $T_{01}$ is the outlet air temperature at the time $\theta_{1}$ when the first combined potential $F_{1}$ wave exits the matrix. Then the number of transfer units for the first combined potential using Eq. (11) is 


$$
\mathrm{N}_{\mathrm{tu}, 1}=2 /\left[(\sigma / \mu)_{1}\right]^{2} \text {. }
$$

The calculation of the number of transfer units for the second combined potential is more complicated. We first need to estimate the difference in the outlet $F_{2}$ at the start and the end of the experiment $\mathrm{F}_{20 e}-\mathrm{F}_{20 \mathrm{~s}^{\circ}}$ This is estimated from

$$
F_{20 e}-F_{20 s}=h_{\text {Oe }}-h_{\text {OS }}+B_{2}\left(w_{\text {oe }}-w_{\text {OS }}\right) \text {, }
$$

where

$$
\beta_{2}=-\left(\frac{\partial h}{\partial w}\right)_{F_{2}}=\frac{h_{\text {int, exp }}-h_{\text {os }}}{w_{\text {os }}-w_{\text {int , exp }}},
$$

where $h_{i n t}$ is the enthalpy of moist air at the

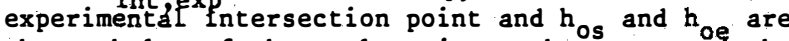
the enthalpy of the outlet air at the start and the end of the run, respectively. The normalized spread of the second combined potential can then be

$$
\left[(\sigma / \mu)_{2}\right]^{2}=\frac{\left(F_{20 e}-F_{2 o s}\right) \int_{\theta}^{\theta} e_{m_{a}^{2}} d F_{20}}{\left(\int_{\theta_{s}}^{\theta} e_{a} m_{a} d F_{20}\right)^{2}}-1 \text {, }
$$

where

$$
\int_{\theta_{s}}^{\theta} \mathrm{m}_{\mathrm{a}}^{\mathrm{n}} \mathrm{dF} \mathrm{F}_{20}=\int_{\theta_{s}}^{\theta_{\mathrm{e}}} \mathrm{m}_{\mathrm{a}}^{\mathrm{n}} \mathrm{dh_{0 }}+\beta_{2} \int_{\theta_{s}}^{\theta_{\mathrm{e}}} \mathrm{m}_{\mathrm{a}}^{\mathrm{n}} \mathrm{dw}, \quad \mathrm{n}=1,2
$$

Note that if the experimental run is terminated before reaching equilibrium, the $F_{2}$ curve is truncated prematurely. Then, assuming a normal distribution for the $F_{2}$ curve, a correction to $F_{20 e}$ is applied.

The number of transfer units for the second combined potential can be estimated using Eq. (15)

$$
\mathrm{N}_{\mathrm{tu}, 2}=2 /\left[(\sigma / \mu)_{2}\right]^{2} \text {. }
$$

Then the Nusselt number for each combined potential can be estimated, as Eq. (3) suggests, from

$$
\mathrm{Nu}_{i}=\operatorname{RePrN} \mathrm{tu}_{i} \mathrm{~A}_{c} / \mathrm{A} \quad \mathrm{i}=1,2 \text {. }
$$

The overall heat transfer Nusselt number and the effective Lewis number can then be easily calculated from Eq. (4). The relation between overall mass transfer and heat transfer Nusselt numbers is:

$$
\mathrm{Nu}_{\mathrm{mo}}=\frac{\mathrm{Nu}_{\mathrm{o}}}{\mathrm{Le}} .
$$

The overall heat transfer coefficient $h$ can be lower than the convective transfer coefficient $h_{c}$ because of the resistance of the stagnant air between particles of various sizes:

$$
\frac{1}{\mathrm{~h}_{\mathrm{o}}}=\frac{1}{\mathrm{~h}_{\mathrm{c}}}+\frac{\delta}{\mathrm{k}_{\mathrm{a}}},
$$

where $\delta$ is the thickness of the stagnant air. This equation easily can be converted to

$$
\mathrm{Nu}_{\mathrm{o}}=\frac{\mathrm{Nu}}{1+\mathrm{Nu} \frac{\delta}{\mathrm{d}_{\mathrm{h}}}},
$$

by using the definition of Nusselt numbers

$$
N u=\frac{h_{c} d_{h}}{k_{a}}, N_{o}=\frac{h_{o} d_{h}}{k_{a}} \text {. }
$$

The overall mass transfer coefficient $b_{m o}$ can be estimated from

$$
\frac{1}{h_{m o}}=\frac{1}{h_{m c}}+\frac{\delta}{\rho_{d} D_{w}}+\frac{d_{p}}{120 \rho_{d} D_{W} n_{a} P_{f}}\left(\frac{\partial w}{\partial W}\right)_{T} \text {, }
$$

where the first term on the right side of the equation is the convective resistance, the second term is the resistance caused by stagnant air $f i l m$, and the third term is the resistance caused by the diffusion of moisture into the particles. The last term is obtained from Equation 118 of Maclainecross $^{19}$ after using the solid-side geometry factor $\eta_{\text {g }}$ to correct for geometry that is not spherically symmetric. Using the definition of effective Lewis number

$$
\text { Le }=\frac{\mathrm{h}_{\mathrm{o}}}{\mathrm{C}_{\mathrm{p}} \mathrm{h}_{\mathrm{mo}}}
$$

and Eq. (22), we can estimate the effective Lewis number from $\mathrm{Nu}$, the dimensions of the matrix, and the properties of the air and the desiccant:

$$
\text { Le }=\frac{\alpha}{D_{w}}+N u_{0} \frac{\zeta_{c}}{n_{a}},
$$

where the solid-side geometry factor coefficient $\zeta_{c}$ is

$$
\zeta_{c}=\frac{1}{60 p_{f}}\left(\frac{d_{p}}{d_{h}}\right)\left(\frac{k_{a}}{\rho_{d} D_{W}}\right)\left(\frac{\partial w}{W}\right)_{t} .
$$

The pressure drop characteristics of a matrix are also needed for design considerations. Using the equation 20

$$
\frac{\Delta P d_{h}}{2 \mu_{m} u_{m} L}=f R e+K \frac{R e_{m} d_{h}}{4 L},
$$

we can find $f R e$ and $\mathrm{K}$ from the intercept and slope of the line that passes through $\Delta \mathrm{P}_{\exp } \mathrm{d}_{\mathrm{h}} / 2 \mu_{\mathrm{m}} \mathrm{u}_{\mathrm{m}} \mathrm{L}$ versus $R_{e_{m}} d_{h} / 4 L$, respectively. To estimate the dehumidifier matrix characteristics from the step transient (or single blow) tests using the method outlined in this section, we developed a program called SINGLEBLOW in Pascal language that runs on an IBM PC or compatible computer. The specifications of the test matrix, such as dimensions and desiccant properties, are entered in the program; the program is run and gives $\mathrm{m}_{d}, \mathrm{C}_{\mathrm{pc}}, \mathrm{Nu}_{1}$, and $\mathrm{Nu}_{2}$ and other pertinent values of the matrix; The details of this program are given elsewhere ${ }^{2 i}$.

The program was checked with transient synthetic data that were generated by heat and mass analogy theory assuming some values of effective mass of dry desiccant, specific heat of the carrier, heat transfer coefficient, and effective Lewis number. The SINGLEBLOW program estimated these values by processing the transient synthetic data with less than $10 \%$ error.

\section{Experimental Method}

\section{The Experimental Test Rig}

The experimental test rig was conceived to perform adiabatic step transient adsorption/desorption experiments of a bench-scale dehumidifier under operating conditions encountered in solar desiccant cooling systems. The schematic of the test rig is shown in Fig. 1. The rig consists of a duct heater, a humidifier, a variable speed blower, an orifice plate, the test section, and instrumentation for measuring temperatures, pressure drops, humidities, and airflow rate. The test section, which contains the test article, temperature 


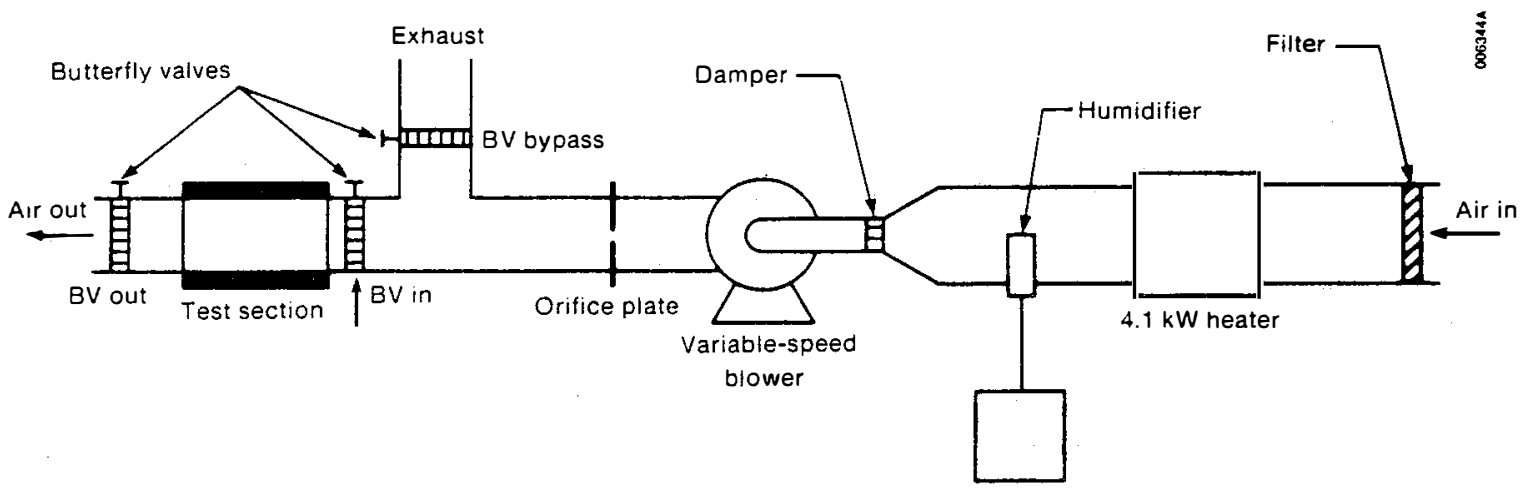

$2 \mathrm{~kW}$ steam generator

Figure 1. Experimental Test Rig

sensors, air samplers, and pressure tap, has. a cross section of $0.161 \mathrm{~m} \times 0.173 \mathrm{~m}$ and is $0.6 \mathrm{~m}$ long. The test section is insulated for adiabatic operation.

The process air can be heated up to $90^{\circ} \mathrm{C}$ by the 4.1-kW finned tubular heater. The process air is humidified up to $0.03 \mathrm{~kg} \mathrm{H} \mathrm{H}_{2} \mathrm{O} / \mathrm{kg}$ dry air by injecting steam produced by a $2-\mathrm{kW}$ atmospheric steam generator. The air is blown through the test rig by $a$ belt-driven blower run by an externally mounted variable-speed motor that can provide air flow rates of 0.0047 to $0.047 \mathrm{~m}^{3} / \mathrm{s}$. Three butterfly valves are used to send air through the test section or through the bypass.

Important quantities to measure in the single blow experiments are inlet and outlet temperatures and humidities, flow rate, and pressure drop across the dehumidifier. The temperature and humidity of air going through the bypass are also measured before introducing the air to the test article. The process air humidity and temperature are controlled by a desk-top computer using a feedback control program. The uncertainty in the voltmeter measurements is less than $0.03 \%$ of the reading with a resolution of $1 \mu \mathrm{V}$.

Temperatures are measured using gauge $30(0.25-\mathrm{mm}-$ diameter) copper-constantan (type T) thermocouple wires. Average inlet and outlet temperatures are obtained by an array of four thermocouples connected in series. The arrays are located in the duct test section to obtain an area weighted average. The electromotive force (emf) produced in this manner is four times the emf of a single thermocouple, and thus the error in reading voltages by the voltmeter is reduced by a factor of four. Sufficient length of bare wires is used to reduce the radiation and conduction errors. An ice box is used as a reference junction for measurement of absolute values of temperatures. The uncertainty in temperature measurement is expected to be less than $0.3^{\circ} \mathrm{C}$.

Air humidity measurements are made using two optical condensation dew-point hygrometers with uncertainties of $10.4^{\circ} \mathrm{C}$. Sample air from the bypass section and inlet and outlet of the test section are drawn through the hygrometers by small pumps from 6.4-mm air samplers mounted in the duct. The uncertainty in calculating the humidity ratios is estimated to be less than $3 \%^{21}$. The fluctuation of

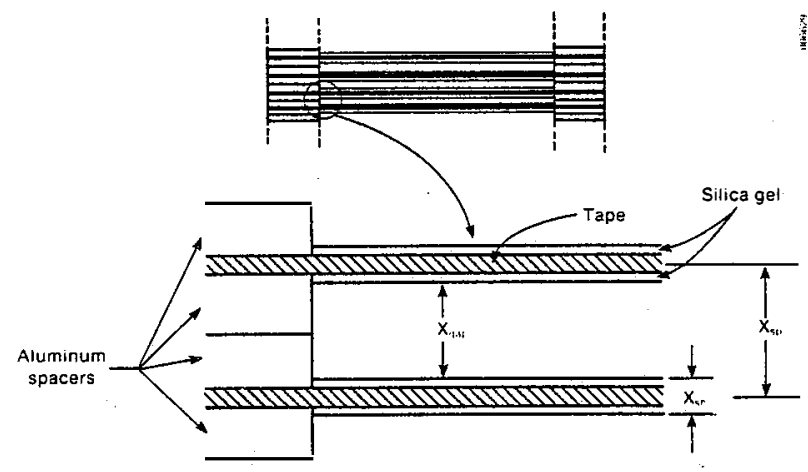

Figure 2. Cross Section of Parallel-Plate Test Article

the inlet air humidity ratio due to the rig characteristics is less than $0.4 \mathrm{~g} / \mathrm{kg}$, which is satisfactory for this study. Air flow rates are determined by an ASME-standard orifice plate with an uncertainty of <5\%. The pressure drop across the orifice plates and the test dehumidifiers were measured using capacitance-type pressure sensors with an uncertainty of $<2.5 \%$.

\section{Description of Test Articles}

Two articles were tested to investigate their performance and determine their characteristics: a crushed silica-gel parallel-plate matrix and a microbead silica-gel staggered parallel-strip matrix.

The parallel-plate matrix has sheets of polyester tape with both sides coated with fine $(177-297-\mu \mathrm{m})$ particles of crushed microporous silica-gel (Davison, W. R. Grace). The sheets with spacers attached to both sides are stacked in a supporting frame and stretched from both ends to make uniform parallel-plate channels. Figure 2 gives a crosssectional view of the parallel-plate test article; Table 1 summarizes its specifications.

The second test matrix investigated had a staggered parallel-strip geometry (Fig. 3). Preliminary calculations showed that this geometry has a higher heat-transfer-coefficient/pressure-drop ratio than that on the parallel plate and may provide more compact dehumidifiers. The same method that we used for the parallel-plate test article was adopted to fabricate the staggered parallel-strip 
Table 1. Specifications of the Parallel-Plate Test Article Dehumidifier

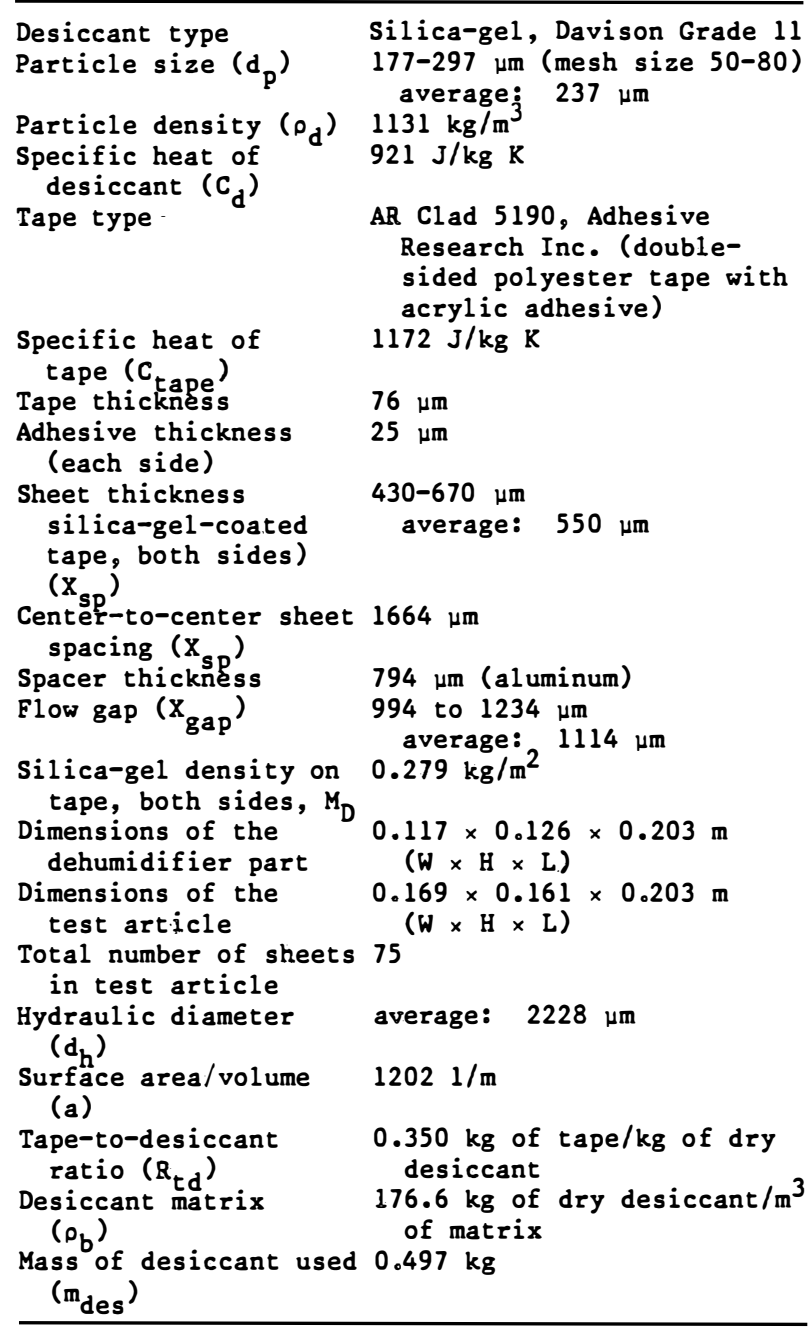

test article. Each sheet in this test article has 12 rows of polyester tape strips $(6.35 \mathrm{~mm}$ long) with both sides of the tape strips coated with fine (74-105 $\mu \mathrm{m})$ particles of microbead microporous silica-gel (from Fuja Davison Chemical Ltd.). The sheets are stacked in a supporting frame to make a staggered parallel-strip geometry. Note that the strips of adjacent sheets are offset to make a 2-mm space between two rows of strips (as in Fig. 3 ). The specifications of this test article are given in Table 2 .

\section{Experimental Procedure}

Adiabatic step transient tests consist of obtaining the transient response of a dehumidifier matrix after a step change in the outlet air state. The inlet and outlet air temperatures and humidity ratios as a function of time are measured until the matrix reaches equilibrium with the inlet air. The matrix is initially at equilibrium with an air that has a different state than the inlet air state before the step change.

Each step transient test basically consists of three parts: matrix conditioning, process air preparation, and transient response. First, the de-

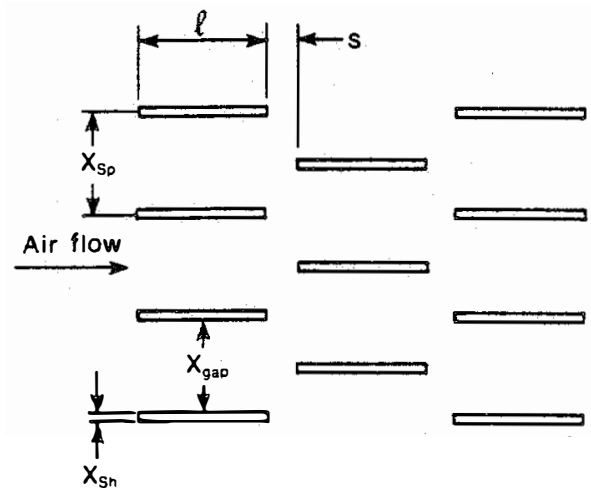

Figure 3. Staggered Parallel-Strip Geometry

\section{Table 2. Specification of First Staggered Parallel-Strip Test Article Dehumidifier}

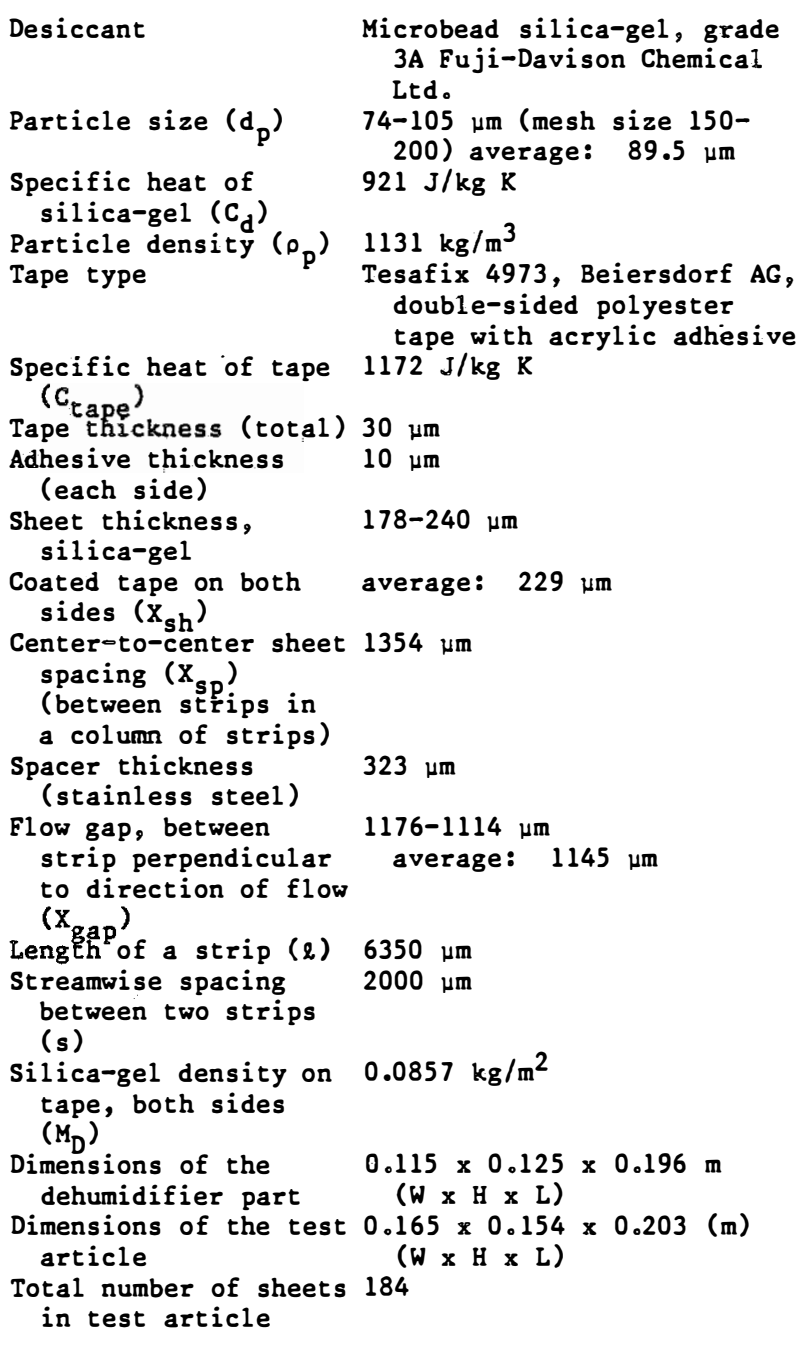

humidifier matrix is conditioned for a uniform state (temperature and desiccant water content) by passing air of a desired condition through it until equilibrium is reached (BV in and BV out open; BV bypass closed). The matrix is then sealed and isolated from the rest of the system (BV in and BV out 
Table 3. Summary of Adiabatic Transient Tests on Parallel-Plate Matrix

\begin{tabular}{|c|c|c|c|c|c|c|c|c|c|c|c|c|}
\hline Run & Date & $\begin{array}{l}P_{t} \\
(P a)\end{array}$ & $(\mathrm{K}) \quad(\mathrm{g} / \mathrm{kg})$ & $(\mathrm{K}) \stackrel{\text { Inlet }}{(\mathrm{g} / \mathrm{kg})}$ & $\begin{array}{l}\text { Intersection } \\
(\mathrm{K}) \quad(\mathrm{g} / \mathrm{kg})\end{array}$ & $\operatorname{Re}$ & $\begin{array}{c}\Delta \mathrm{P} \\
(\mathrm{Pa})\end{array}$ & fRe & $R_{d}$ & $c_{p c}$ & $\mathrm{Nu}_{1}$ & $\mathrm{Nu}_{2}$ \\
\hline 6 & $11 / 18 / 85$ & 80433 & $301.0 \quad 12.9$ & $316.2 \quad 14.9$ & $306.4 \quad 17.5$ & 209.8 & 107.4 & 24.71 & 0.760 & 2329 & 3.283 & 4.546 \\
\hline 7 & $11 / 18 / 85$ & 80508 & $313.3 \quad 12.0$ & 303.415 .1 & $313.8 \quad 12.1$ & 212.1 & 104.5 & 25.10 & 0.734 & 1118 & 0.000 & 1.902 \\
\hline 12 & $11 / 18 / 85$ & 80732 & $301.8 \quad 13.7$ & $334.5 \quad 15.2$ & 310.421 .1 & 216.5 & 122.8 & 24.79 & 0.635 & 4201 & 5.574 & 27.188 \\
\hline 13 & $11 / 23 / 85$ & 81331 & $322.3 \quad 8.3$ & $304.5 \quad 15.1$ & $327.8 \quad 10.6$ & 212.7 & 106.2 & 24.77 & 0.537 & 0 & 1.396 & 1.521 \\
\hline 14 & $11 / 21 / 85$ & 80594 & 297.011 .5 & $335.0 \quad 15.1$ & 308.320 .9 & 298.4 & 177.1 & 25.92 & 0.427 & 4759 & 0.000 & 15.162 \\
\hline 15 & $11 / 21 / 85$ & 80900 & $329.1 \quad 10.8$ & $304.4 \quad 15.1$ & $327.9 \quad 10.4$ & 312.7 & 168.8 & 26.63 & 0.336 & 3965 & 0.000 & 2.493 \\
\hline 16 & $11 / 22 / 85$ & 81014 & 302.514 .0 & $335.6 \quad 15.1$ & 310.121 .3 & 411.9 & 262.2 & 27.38 & 0.735 & 3206 & 9.910 & 14.402 \\
\hline 17 & $11 / 22 / 85$ & 80721 & $332.1 \quad 11.6$ & $304.8 \quad 15.1$ & $328.4 \quad 9.5$ & 430.6 & 246.0 & 27.95 & 0.618 & 1678 & 0.000 & 2.325 \\
\hline 18 & $11 / 19 / 85$ & 81725 & $302.1 \quad 13.8$ & $352.5 \quad 15.0$ & $312.6 \quad 24.6$ & 212.4 & 129.0 & 24.34 & 0.732 & 3760 & 5.033 & 11.190 \\
\hline 19 & $11 / 20 / 85$ & 81547 & $334.8 \quad 6.9$ & $305.8 \quad 15.3$ & $336.7 \quad 7.0$ & 211.8 & 107.8 & 24.69 & 0.555 & 9906 & 0.000 & 0.971 \\
\hline 24 & $11 / 20 / 85$ & 81888 & $305.5 \quad 6.1$ & $304.8 \quad 17.0$ & 316.113 .2 & 212.7 & 101.8 & 24.66 & 0.729 & 2407 & 4.729 & 2.372 \\
\hline 25 & $11 / 20 / 85$ & 81671 & $301.6 \quad 13.9$ & $307.3 \quad 6.9$ & $297.3 \quad 10.1$ & 209.4 & 97.8 & 24.86 & 0.797 & 4861 & 0.000 & 4.623 \\
\hline
\end{tabular}

Table 4. Summary of Adiabatic Transient Tests on the Staggered Parallel-Strip Matrix

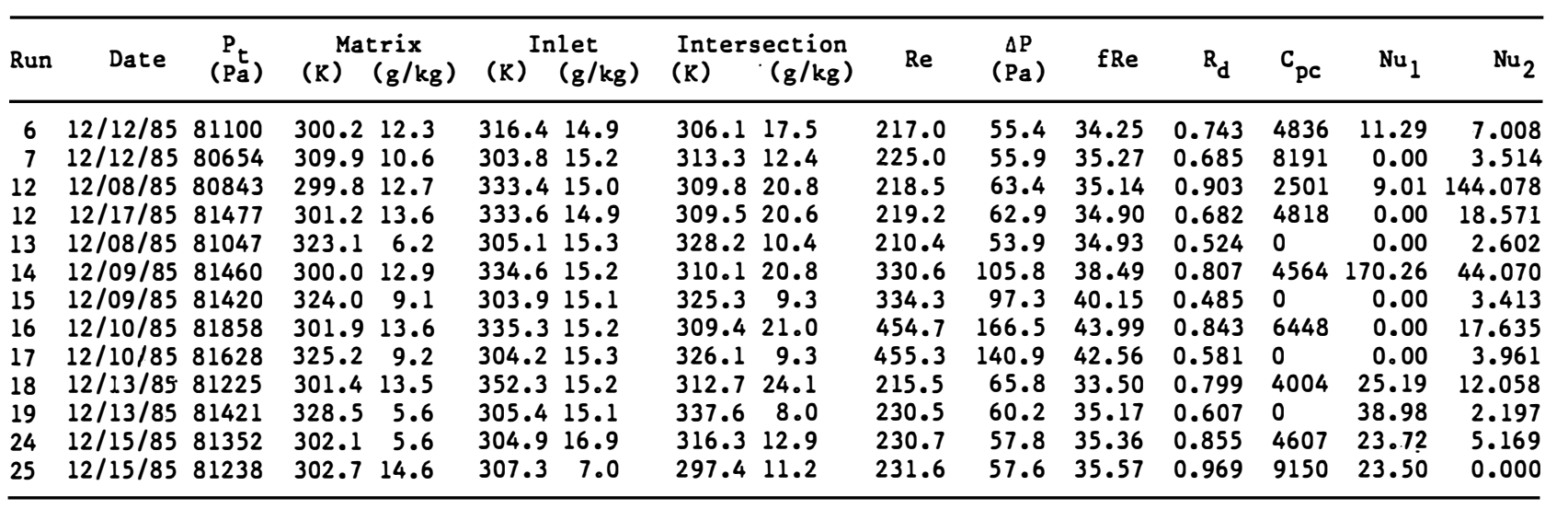

closed; BV bypass open). Then, the process airstream is brought up to a new state while it passes through a bypass section. When the process air reaches the desired humidity, temperature, and flow rate, it is abruptly introduced to the matrix (by opening BV out and closing BV bypass and opening BV in simultaneously), and the transient response is obtained. If the initial state of the matrix is drier than that of the process air, the test is called adsorption or dehumidification. A desorption or regeneration test occurs when the process air is drier than the initial state of the matrix. The detail descriptions of the test rig, the test articles, and the experimental procedure are given elsewhere 21 .

\section{Results and Discussion}

The adiabatic step transient data obtained at the test rig for the parallel-plate and the staggered parallel-strip matrices are presented and analyzed here by the SINGLEBLOW program. Tables 3 and 4 summarize the conditions of the tests performed on parallel-plate and staggered matrices, respectively. Because of space limitation, only eight of these tests are presented in graphical form. Here Figs. 4-11 should be observed with the following considerations:

- Before the step change--i.e., before process air is introduced to the matrix--no air flows through the test section. Therefore, the readings of the inlet and outlet thermocouples that are in the test section have a large radiation error, especially for desorption (or regeneration) experiments. This can be seen from the initial difference between the inlet and the outlet temperatures on the figures.

- The step change in inlet temperature deviates from an ideal (square) step change because of the existence of the thermal mass of the ducts and the inlet valve between the bypass and the test matrix. The inlet temperature changes exponentially to its final value in less than $15 \mathrm{~s}$. Note that in our analysis using the SINGLEBLOW program, the difference between the inlet and outlet air temperatures is used to calculate the slope of the $F_{i}$ curves. This reduces the error introduced by the nonideal step change.

- The inlet and outlet dew-point hygrometer sensors respond about $5 \mathrm{~s}$ after the inlet and outlet thermocouples respond because a small sample of air should be pumped from the test section to the hygrometer sensors.

- Usually there is an overshoot in the inlet air humidity ratio caused by the way the hygrometer sensors detect the dew-point temperature. This overshoot (e.g., experiment 13 of parallel-plate matrix) is not caused by the responses of the steam generator. In our analysis using the SINGLEBLOW program, we ignored this overshoot and assumed an ideal step change in the inlet air humidity ratio $5 \mathrm{~s}$ after the temperature change started.

- The transient response curves of the matrices are better defined for the desorption (regeneration) experiments than for the adsorption cases because of the self-sharpening effect of the adsorption 

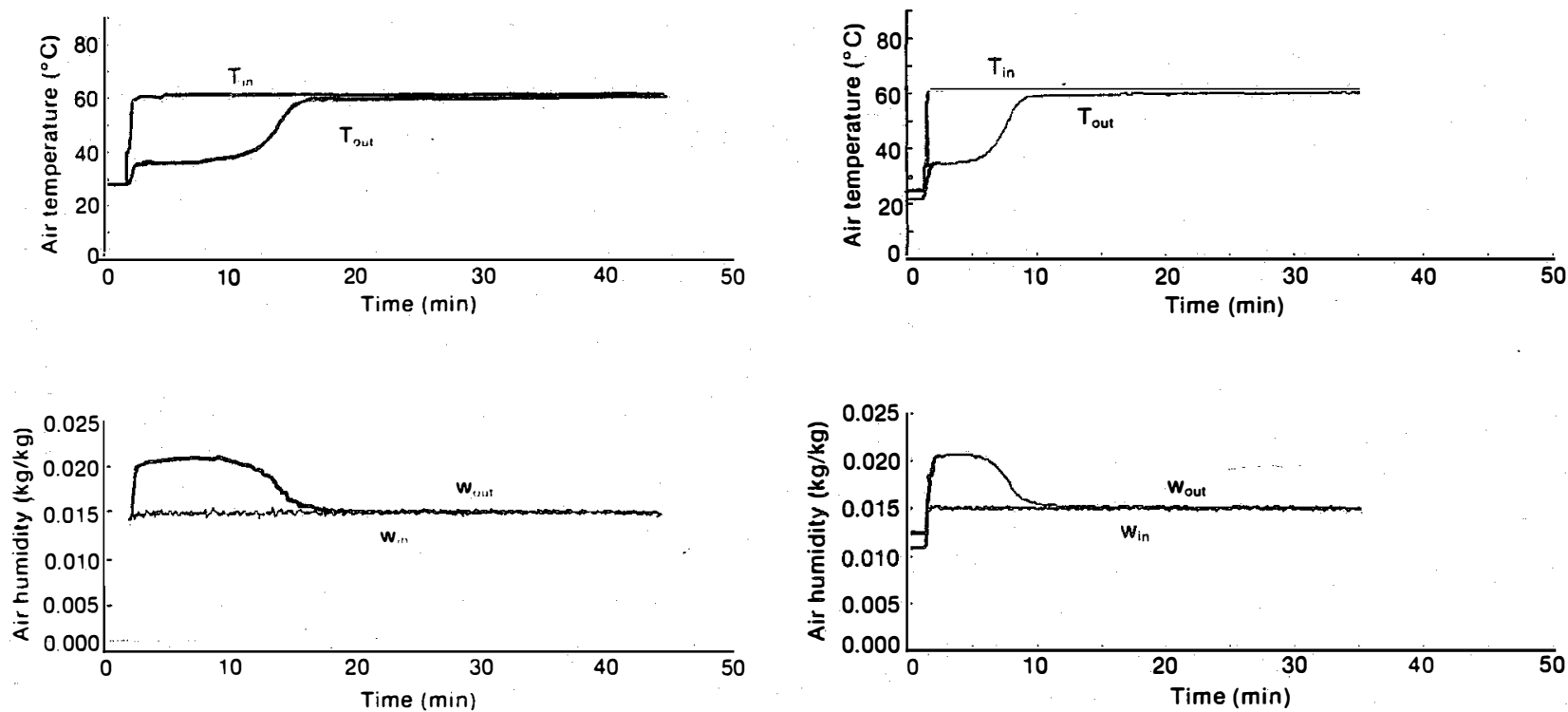

Figure 4. Results of Experiment No. 12 ParallelPlate Matrix
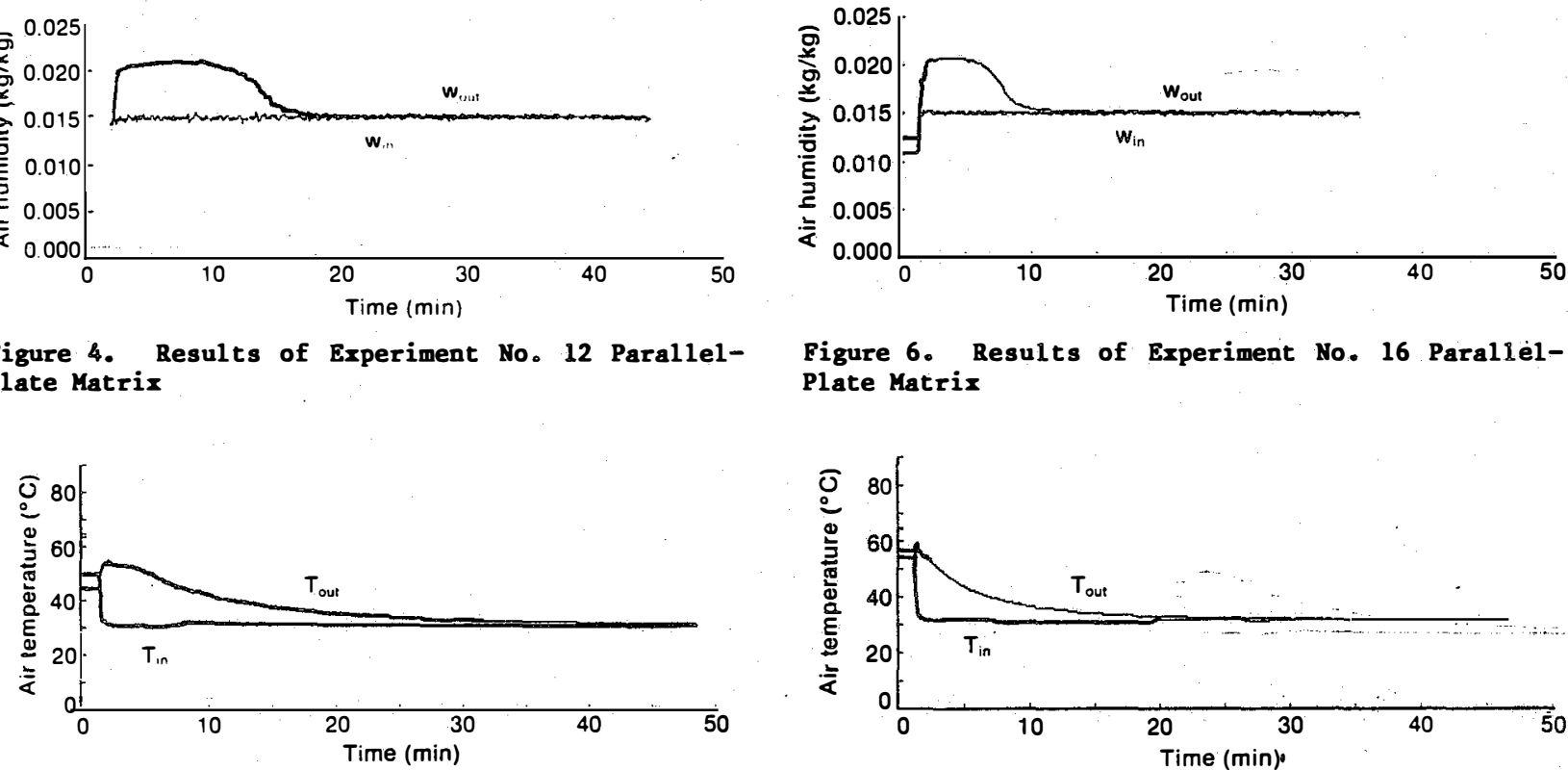

Figure 6. Results of Experiment No. 16 ParallèPlate Matrix
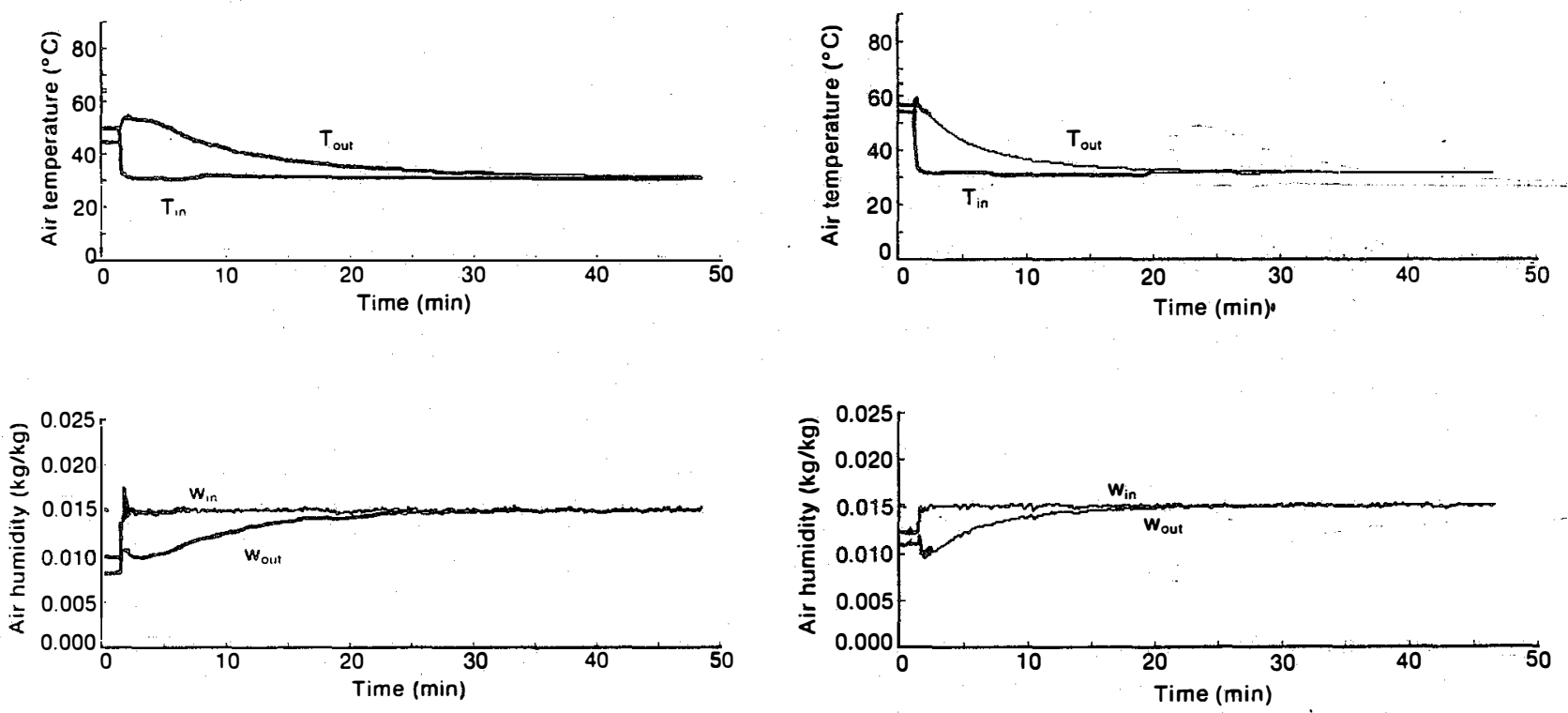

Figure 5. Results of Experiment No. 13 ParallelPlate Matrix

isotherm on the wave fronts. The wave fronts are broadened for the adsorption cases. The first wave, especially for the adsorption runs, is sometimes combined with the transient behavior of the sensors and is hard to detect.

- The staggered parallel-strip matrix reaches equilibrium with the inlet air faster than the parallel-plate matrix because the former one has less silica gel (about one-fourth). The first and second waves pass through staggered matrix faster than through the other one.

The adiabatic step transient data obtained for the two test dehumidifier matrices are analyzed with the combined "moments method" and "analogy theory" using the SINGLEBLOW program. Tables 3 and 4 presant the results of interpreting the data for the two matrices using this program.

Figure 7. Results of Experiment Ho. 17 ParallelPlate Matrix

We found that for some experiments unreasonable negative values for either $\mathrm{C}_{2}, \mathrm{Nu}_{1}$, or $\mathrm{Nu}_{2}$ are estimated. These negative values are replaced with zeros, which are shown on Tables 3 and 4 and were not included in the reported averages. The reasons for these negative estimations follow:

- The profile of the first wave for some of the experiments cannot be detected correctly because the exit of the first wave overlaps with responses of the measurement sensors (e.g., run 13 for parallel-plate matrix). This effect is even more pronounced when a small mass of desiccant is used in the matrix (e.g., runs 13 and 17 for staggered matrix). The estimation of $\mathrm{Nu}_{1}$ is very sensitive to the profile of the first combined potential wave that passes through the matrix. 

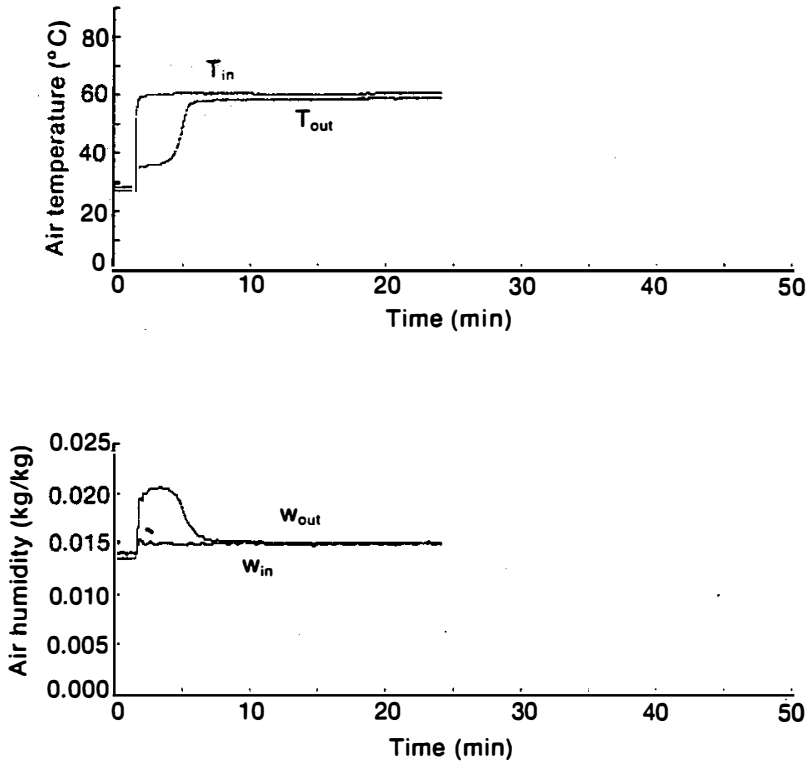

Figure 8. Results of Experiment Mo. 12 Staggered Matrix
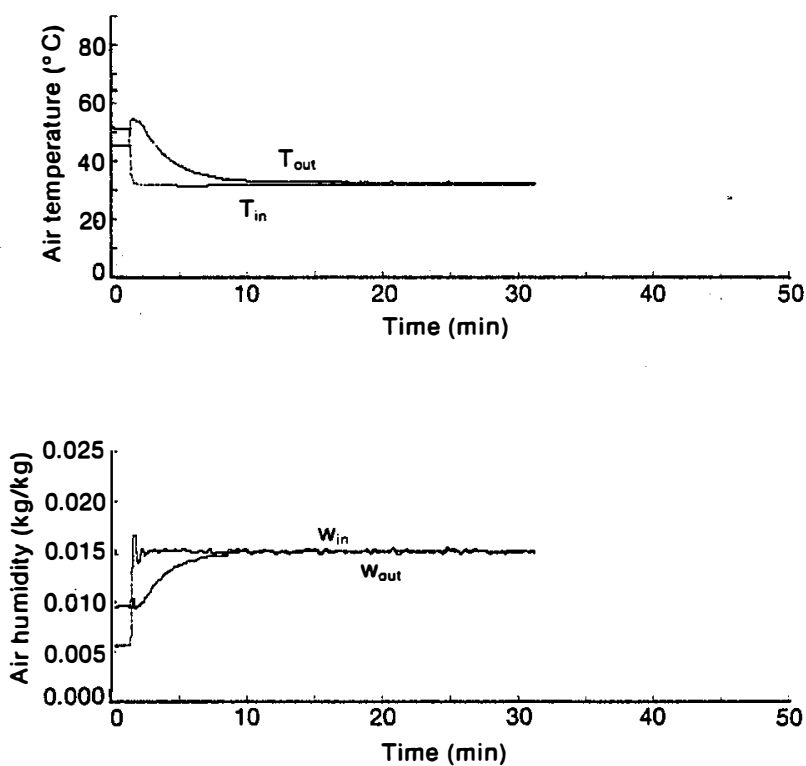

Figure 9. Results of Experiment Mo. 13 Staggered Matrix

- The SINGLEBLOW program assumes that the matrix is initially at a uniform state. After running the tests and obtaining experience with the experimental facility, we believe it may not be true and some of the erroneous estimations can be caused by the nonuniformity of the initial state of the matrix.

In the adsorption tests the matrix is first dried with hot air, then it is sealed for about $45 \mathrm{~min}$ while the humid and colder process air for the step change is prepared. In the meantime, the matrix cools down but nonuniformly because of different radiation losses at both ends of the matrix. The core of the matrix also cools down slower than the ends. For desorption tests the matrix is first loaded with moisture at relatively low temperatures
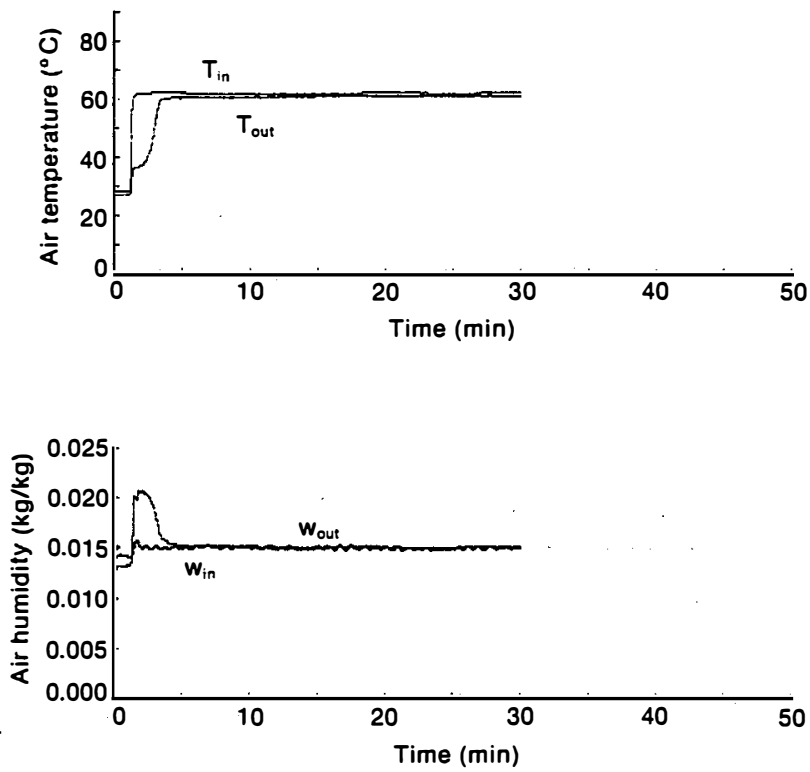

Figure 10. Results of Experiment No. 16 Staggered Matrix
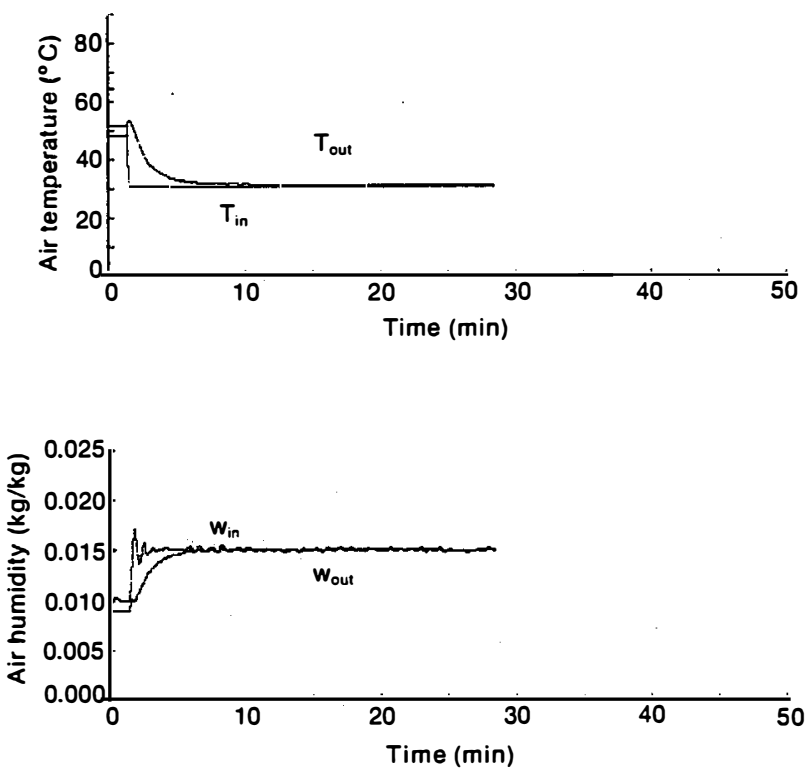

Figure 11. Results of Experiment No. 17 Staggered Matrix

and then sealed for about $45 \mathrm{~min}$ while the hot process air for the step change is prepared. In the meantime, the end of the matrix that is closer to the bypass section may warm up because of heat conduction from the hot air that flows through the bypass section.

This effect will also cause a nonuniform state in the matrix. Consequently, the nonuniformity of the matrix is more pronounced in the adsorption runs than in the desorption runs. The nonuniform matrix state causes a less accurate estimation of $\mathrm{Nu}_{1}$, as shown in Tables 3 and 4 . The even numbered runs except run 24 are desorption runs, and all the odd numbered runs except run 25 are adsorption runs. $\mathrm{Nu}$ for most of the adsorption runs is not estimated correctly. Note that the value of $\mathrm{Nu}_{2}$ is 
Table 5. Summary of Means and Errors of the Estimated Results

\begin{tabular}{|c|c|c|c|c|c|c|c|c|c|c|}
\hline \multirow{2}{*}{$\begin{array}{c}\text { Dehumidifier } \\
\text { Matrix }\end{array}$} & \multicolumn{2}{|r|}{$\mathrm{R}_{\mathrm{d}}$} & \multicolumn{2}{|c|}{$c_{c p} *(J / k g K)$} & \multicolumn{2}{|c|}{$\mathrm{Nu}_{1} *$} & \multicolumn{2}{|r|}{$\mathrm{Nu}_{2}^{*}$} & \multicolumn{2}{|r|}{$f R e$} \\
\hline & mean & \% error & mean & $\%$ error & mean & $\%$ error & mean & \% error & mean & $\%$ error \\
\hline Parallel Plate & 0.633 & 7 & 3180 & 26 & 3.88 & 29 & 3.48 & 27 & 25.48 & 2 \\
\hline $\begin{array}{l}\text { Staggered } \\
\text { Parallel Strip }\end{array}$ & 0.729 & 6 & 4943 & 18 & 22.42 & 30 & 6.57 & 28 & 36.87 & 3 \\
\hline
\end{tabular}

Note: \% error is based on standard deviation/mean/square root (no. of data points).

*Zeros for estimation of these values are omitted.

estimated independently of $\mathrm{C}_{\mathrm{pc}}$ and $\mathrm{Nu}_{1}$ and is the most reliable estimated parameter of the three.

Table 5 shows that the mean values of the effective mass of gel. The ratio $R_{d}$ for parallel-plate and staggered matrices are 0.633 and 0.729 , respectively, with a mean relative error of less than $7 \%$. The effective mass of silica gel is lower than the actual gel in each of the matrices possibly because adhesive penetrated some of the pores of the gel and thus reduced the gel's water absorption capacity. The effective mass of the desiccant in the parallel-plate matrices is about $15 \%$ lower than that of the staggered one. A thicker adhesive layer in the parallel matrices and a longer period of use can explain the difference between the effective masses in the two dehumidifier matrices. See Tables 1 and 2 for the desiccant particle sizes and adhesive thicknesses in the two matrices. The parallel-plate matrices were fabricated in March 1985 and tested in November 1985, and the staggered matrices were fabricated in October 1985 and tested in December 1985 .

Using values of $\overline{\mathrm{Nu}}_{i}$, one can estimate values of $\overline{\mathrm{Nu}}$ and $\overline{\mathrm{Le}}$ from Eq. (4) and $\eta_{\text {f }}$ from Eq. (24). Note that the required values of $a_{j} / \alpha_{j}, \zeta_{c}$, and $\alpha / D$ for the calculations are outputs of the SINGLEBLOW program. Unfortunately, using the estimated $\overline{\mathrm{Nu}}_{1}$ and $\overline{\mathrm{Nu}}_{2}$, we obtained values of $\overline{\text { Le }}$ smaller than $\alpha / D_{w}$, and $\eta$ less than that are not physically possible. We believe this is caused by improper values of $\mathrm{Nu}_{1}$. Since the values of $\mathrm{Nu}_{2}$ and thus $\overline{\mathrm{Nu}}_{2}$ are more dependable, we used the values of $\mathrm{Nu}_{2}$ and assumed a solid-side geometry factor $n_{a}=1$.

Using Eqs. (4) and (24) with $\eta_{a}=1$, we found (Table 6) that the overall heat transfer Nusselt numbers were 3.59 and 6.68 for parallel-plate and staggered matrices, respectively, and the mean Le is about 1 for both matrices. The overall Nusselt numbers were about $50 \%$ lower than the convective values based on laminar flow theories in the two matrices 21 . One explanation is that the overall heat transfer coefficient is lower than the convective transfer coefficient because of the thermal resistance of stagnant air film between the particles of various sizes, as suggested by Eq. (20). We estimated the values of the stagnant air film thickness $\delta$ to be $0.313 \mathrm{~mm}$ and $0.107 \mathrm{~mm}$ for the parallel-plate and staggered matrices, respectively, which means that the air film is almost as thick as the average particle size in both test matrices. In other words, particles on the tapes project, almost twice as much as the average particles, in the flow channels. This is possible for the crushed particles in the parallelplate matrix but not for the more uniform spherical
Table 6. Summary of Results Based on $\mathrm{Nu}_{2}$ and $n_{a}=1$

\begin{tabular}{lcccccc}
\hline $\begin{array}{l}\text { Dehumidifier } \\
\text { Matrix }\end{array}$ & $\mathrm{Nu}_{2}$ & $\mathrm{Nu}_{0}$ & Le & $\begin{array}{c}\delta \\
(\mathrm{mm})\end{array}$ & $\delta / \mathrm{d}_{\mathrm{p}}$ & $\mathrm{Nu}_{\mathrm{o}} / \mathrm{fRe}$ \\
\hline Parallel Plate & 3.48 & 3.59 & 1.14 & 0.313 & 1.06 & 0.141 \\
Staggered & & & & & & \\
Parallel Strip & 6.57 & 6.68 & 1.06 & 0.107 & 1.02 & 0.181 \\
\hline
\end{tabular}

particles of the staggered matrix. The reason for low overall heat transfer coefficients and whether it can be explained by the stagnant air film should be investigated further.

The ratio of $\overline{\mathrm{Nu}} / \mathrm{fRe}$ (heat or mass transfer performance to pressure drop ratio) is a measure of the size of a heat or mass exchanger 21 . As this ratio increases, the total volume (or size) of the exchanger decreases. The value of $\mathrm{Nu}_{0} / f R e$ for staggered parallel-strip matrix is about $28 \%$ higher than that of parallel-plate matrix (see Table 6). Therefore, a smaller diameter rotary dehumidifier can be made with the staggered parallel-strip matrix using microbead silica-gel.

\section{Conclusions}

Adiabatic step transient data were obtained for a crushed silica-gel, parallel-plate matrix and a microbead silica-gel, staggered parallel-strip matrix in an experimental test rig. A methodology to analyze these adiabatic step transient tests was developed that combined the moments method and the analogy theory. By analyzing the data using this methodology, we found that:

- $63.3 \%$ and $72.9 \%$ of the mass of the desiccant were effective in the parallel-plate and staggered parallel-strip matrix dehumidifiers, respectively, because gel pores were blocked by adhesive. The uncertainty in these estimations was about $15 \%$ 。

- Estimating the Nusselt number from the second combined potential was more dependable than estimating the Nusselt number from the first combined potential. This was attributed to the nonuniform initial state of the matrix, deviation from the ideal step change in the inlet air temperature, and mixing of the first combined potential wave with the responses of the measurement sensors when the first wave exited the matrix quickly.

- The mean effective Lewis numbers for both matrices were about 1 , and the mean overall Nusselt numbers for both dehumidifier matrices 
were about $40 \%$ to $50 \%$ lower than convective Nusselt numbers predicted by laminar-flow theories. This was attributed to the resistance in the stagnant air film between the differentsize particles.

- The mean overall Nusselt number of the staggered matrix was about $85 \%$ larger than that of the parallel-plate matrix, which may be caused by the enhanced gas-side transfer process or the use of a better desiccant (small spherical, microbead silica gel compared with larger crushed silica gel) in the staggered matrix.

- The value Nu/fRe microbead silica gel of the staggered parallel strip matrix was about $28 \%$ larger than that of the crushed silica-gel parallel-plate matrix. Using the geometry and material combination of the staggered matrix, a smaller dehumidifier can be fabricated.

\section{Acknowledgments}

This work was supported by the Solar Buildings Research and Development Program of the U.S. Department of Energy's Office of Solar Heat Technologies. The authors would like to thank E. Van den Bulck for his contribution to the experimental part of this work.

\section{References}

1. Jurinak, J. J., "Open Cycle Desiccant Cooling-Component Models and Systems Simulations," Ph.D. Dissertation, Madison, WI: University of Wisconsin, Solar Energy Laboratory, 1982.

2. Nienberg, J. W., "Modeling of Desiccant Performance for Solar-Desiccant-Evaporative Cooling Systems," M.S. Thesis, Los Angeles: University of California, 1977.

3. Bullock, C. E., and J. L. Threlkeld, "Dehumidification of Moist Air by Adiabatic Adsorption," Trans. Am. Soc. Heat Refrig. AirCondit. Eng. Vol. 72, 1966, pp. 301-313.

4. Pla-Barby, Fo E., G. C. Vliet, and R. L. Panton, "Performance of Rotary Bed Silica-Gel Solid Desiccant Dryers," ASME 78-h-36, presented at the ASME Annual Meeting, 1978.

5. Pesaran, A. A., and A. F. Mills, "Modeling of Solid-Side Mass Transfer in Desiccant Particle Beds," presented at the ASME 6th Solar Energy Conference, 8-12 April 1984, Las Vegas, NV.

6. Kutscher, C. F., and R. S. Barlow, Dynamic Performance of Packed-Bed Dehumidifiers: Experimental Results from the SERI Desiccant Test Laboratory, SERI/TR-252-1429, Golden, CO: Solar Energy Research Institute, Aug. 1982.

7. Wurm, et al., Solar-MEC ${ }^{C}$-Development ProgramAnnual Program Report, 000-4495-15, Chicago, IL: Institute of Gas Technology, 1979.

8. Gidaspow, D., 2. Lavan, M. Onischak, and S. Perkari, "Development of a Solar Desiccant Dehumidifier, Proceedings of 3rd Workshop on the
Use of a Solar Energy for the Cooling of Buildings, 1978, pp. 83-89.

9. Kim, S., P. Biswas, and A. F. Mills, "A Compact Low-Pressure Drop Desiccant Bed for Solar AirConditioning Application, 2: Bench Scale Tests, J. Solar Energy Eng., Vol. 107, 1985, pp. 120-127.

10. Schlepp, D., and R. Barlow, Performance of the SERI Parallel-Passage Dehumidifier, SERI/TR-2521951, Golden, CO: Solar Energy Research Institute, Sept. 1984 .

11. Ruthven, D. M., Principles of Adsorption and Adsorption Processes, New York, John Wiley \& Sons, Inc. 1984 .

12. Jefferson, C. P., "Dynamic of Packed Beds with Intraphase Heat and Mass Transfer," Chemical Engineering Science, Vol. 23, 1968, pp. 509-523.

13. Henry, P. S. H., "Diffusion in Adsorbing Media," Proceedings of the Royal Society, Ser. A, Vol. 171, 1939, Pp. 215-241.

14. Close, D. J., and P. J. Banks, "Coupled Equilibrium Heat and Single Adsorbate Transfer in Fluid Flow through a Porous Medium--II Predictions for a Silica-Gel Air Drier Using Characteristic Charts," Chem. Engng. Sci., Vol. 27, 1972, pp. $1157-1169$.

15. Banks, P. J., "Coupled Equilibrium Heat and Single Adsorbate Transfer in Fluid Flow through a Porous Medium--I Characteristic Potentials and Specific Capacity Ratios," Chem. Engng. Sci., Vol. 27, 1972, pp. 1143-1155.

16. Banks, P. J., D. J. Close, and I. L. Maclainecross, "Coupled Heat and Mass Transfer in Fluid Flow through Porous Media--An Analogy with Heat Transfer," Proc. 4th Int. Heat Transfer Conf., Versailles, 1970 .

17. Anzelius, A., "über Erwärmug vermittels durchstromender Medien," A. Angew, Math. Mech., Vol 6, 1926, pp. 291-294.

18. Kays, W. M., and A. L. London, Compact Heat Exchangers, New York: McGraw-Hill, 1964.

19. Maclaine-cross, I. L., "A Theory of Combined Heat and Mass Transfer in Regenerators," Ph.D. Dissertation, Australia: Monash University, Department of Mechanical Engineering, 1974.

20. Ambrose, C. W., I. L. Maclaine-cross, and E. B. Robson, The Use of Rotary Regenerative Heat Exchangers for the Conservation of Energy in Buildings, Final Report Project 109, Canberra, Australia: National Energy Research Development and Demonstration Committee, Australian Government, 1983.

21. Pesaran, A. A., I. L. Maclaine-cross, and E. Van den Bulck, Measurements on Promising Dehumidifier Materials and Geometries, SERI/TR-2522898, Golden, CO: Solar Energy Research Institute, forthcoming. 